\title{
GEOPROCESSAMENTO APLICADO AO USO E OCUPAÇÃO DA TERRA NA BACIA HIDROGRÁFICA DO RIBEIRÃO SÃO PEDRO- BOTUCATU (SP)
}

\author{
Aline Kuramoto Gonçalves ${ }^{1}$
}

Gabriel Rondina Pupo da Silveira ${ }^{2}$

Mariana de Campos ${ }^{3}$

\begin{abstract}
RESUMO
O presente artigo tem como objetivo a contribuição em discriminar, mapear e quantificar as áreas de uso e ocupação da terra da bacia hidrográfica do Ribeirão São Pedro - Botucatu (SP), com a utilização de técnicas de sensoriamento remoto - obtido por imagem de satélite de 2011 - e do uso de geoprocessamento. Para tanto, utilizou-se de técnicas de geoprocessamento, sendo a integração de informações realizada no Sistema de Informações Geográficas (SIG) - IDRISI, aliada ao uso de cartas planialtimétricas, editada pelo Instituto Brasileiro de Geografia e Estatística - IBGE, escala 1:50.000 e imagem de satélite LANDSAT - 5 (2011) sensor TM (Thematic Mapper) com resolução espacial de $30 \mathrm{x}$ 30 metros, cedidas pelo Instituto Nacional de Pesquisas Espaciais (INPE). Desta forma, o estudo de da bacia hidrográfica torna-se uma ferramenta importante para entender sua dinâmica em relação ao uso e ocupação de sua área e caracterizar os seus problemas ambientais.
\end{abstract}

PALAVRAS-CHAVE:Bacia Hidrográfica, SIG, monitoramento ambiental.

\footnotetext{
${ }^{1}$ Geógrafa, Mestranda em Agronomia, UNESP/FCA. aline587@gmail.com.

2 Eng ${ }^{\circ}$ Agrônomo, Mestrando em Agronomia, UNESP/FCA, gabrielrondina@hotmail.com

${ }^{3}$ Bióloga, Mestranda em Agronomia, UNESP/FCA, marianacampos03@gmail.com
} 


\title{
GIS APPLIED TO THE USE AND OCCUPATION OF WATERSHED RIBEIRÃO SÃO PEDRO- BOTUCATU (SP)
}

\begin{abstract}
This article aims to contribution to discriminate, to map and quantify the areas of land use and occupation of the watershed of the Ribeirão São Pedro - Botucatu (SP), with the use of remote sensing techniques - image obtained by satellite 2011 - and the use of GIS. For this, we used the GIS techniques and the integration of information held in the Geographic Information System (GIS) - IDRISI, coupled with the use of cartographic maps, published by the Brazilian Institute of Geography and Statistics - IBGE, scale 1: 50,000 and LANDSAT satellite image - 5 (2011) sensor TM (Thematic Mapper) with spatial resolution of $30 \times 30$ meters, provided by the National Institute for Space Research (INPE). Thus, the study of the watershed becomes an important tool to understand its dynamics in relation to the use and occupation of their area and to characterize their environmental problems.
\end{abstract}

KEY-WORDS: Watershed, GIS, environmental monitoring.

\section{SIG APLICADO AL USO Y OCUPACIÓN DE LA TIERRA EN CUENCA RIBEIRÃO SÃO PEDRO- BOTUCATU (SP)}

\section{RESUMEN}

Este artículo de AIMS Contribución para discriminar, para trazar y cuantificar las áreas de uso y ocupación del suelo de la cuenca del Ribeirão São Pedro - Botucatu (SP), con el uso de técnicas de teledetección - imagen obtenida por satélite en 2011 - y el uso de los SIG. Para ello, hemos utilizado las técnicas de SIG, y la integración de la información contenida en el Sistema de Información Geográfica (GIS) - IDRISI, junto con el uso de los mapas cartográficos, publicado por el Instituto Brasileño de Geografía y Estadística - IBGE, a escala 1: 50.000 y la imagen de satélite LANDSAT - 5 (2011) del sensor TM (Thematic Mapper) con una resolución espacial de 30 x 30 metros, proporcionada por el Instituto Nacional de Investigaciones Espaciales (INPE). Por lo tanto, el estudio de la cuenca se convierte en una herramienta importante para entender su dinámica en relación con el uso y la ocupación de su área y para caracterizar sus problemas ambientales.

PALABRAS-CLAVE Cuenca, GIS, vigilancia del medio ambiente.

\section{INTRODUÇÃO}

O estudo em bacia hidrográfica é complexo, conforme Criado e Piroli (2012), nessa unidade geográfica é "possível observar elementos diversos, como biomas diferentes, clima diferente, nível de intervenção humana variando, dentro outros".

Por meio dos seus elementos e variáveis naturais diversos em relação à bacia hidrografia, destaca-se a análise ao uso e ocupação das terras, no que tange o homem em apropriar-se do meio natural que ocorre muitas vezes de maneira 
inadequada. Em decorrência disso, ocasiona os diversos fatores a problemas ambientais.

De acordo com Lepsch (2010) a humanidade sempre esteve dependente dos recursos naturais como o ar, água e solos de boa qualidade para continuar a viver. Contudo, o modo de como o homem se apropriou e se apropria desses recursos naturais nem sempre são de forma a preserva-lós.

Assim, Bertoni e Neto (2010) discorrem que:

Os recursos naturais de caráter renovável com que a Natureza nos aquinhou, ou seja, o solo propriamente dito, as florestas, a fauna silvestre, a água usada pelas plantas, às fontes, cujo uso e proteção adequados se convencionou denominar amplamente de conservação do solo, têm sido impiedosamente malbaratados por uma verdade agricultura de exploração (BERTONI; NETO, 2010, p.13).

Diante disso, este artigo apresenta o estudo da bacia hidrográfica Ribeirão São Pedro que pertence ao município de Botucatu (SP) e, está inserido nos limites da Unidade de Gerenciamento de Recursos Hídricos do Médio Tietê- UGRHI 10, conforme a política estadual de gestão de recursos hídricos do Estado de São Paulo. No que tange a bacia hidrográfica em estudo avaliou o cenário do uso e ocupação da terra no ano de 2011. De maneira a contribuir em discriminar, mapear e quantificar as áreas de uso e ocupação da terra da bacia hidrográfica.

Aferiu que a maior parte do uso e ocupação da terra na bacia hidrográfica do Ribeirão São Pedro é coberta pela pastagem, assim um dos maiores déficit é certamente a vegetação, mesmo nas áreas marginais aos cursos d'água do ribeirão. De acordo com Santos (2012), a ação do homem em modificar a dinâmica natural, sem considerar sua dinâmica natural, desencadeia processos degradativos no meio ambiente ou mesmo contribui para o seu aceleramento, como exemplo os processos de erosão.

O processo de erosão é um fenômeno natural que ocorre de forma lenta, sem causar maiores problemas ao meio. No entanto, este processo pode ser apressado pela ação do homem, sendo as principais causas da erosão acelerada: o desmatamento; as práticas agrícolas inadequadas; a ocupação incorreta de áreas, tais como de 
encostas, de margem de recursos hídricos, de terrenos mais sujeitos à erosão; alteração no escoamento natural da águas; movimentos de terra como os aterros e escavações; impermeabilização de terrenos (MOTA, 1995, p.122 apud SANTOS, 2012, p.4).

A utilização de técnicas de geoprocessamento configurou-se como uma ferramenta importante para avaliar a expansão das atividades agropecuárias, sem considerar as potencialidades e limitações quando ao uso das terras, constitui uma fonte potencial de degradação do meio ambiente da bacia hidrografia do ribeirão São Pedro.

\section{DESENVOLVIMENTO}

O uso e cobertura da terra é um aspecto importante no entendimento da dinâmica presente no espaço geográfico, conforme SANTOS (2013) "haja vista ser onde ocorre a relação sociedade-natureza. Compreende-se também que a mesma se expressa na paisagem e traz consigo tais marcas". De acordo com IBGE (2013):

O conhecimento sobre o uso da terra ganha relevo pela necessidade de garantir sua sustentabilidade diante das questões ambientais, sociais e econômicas a ele relacionadas e trazidas à tona no debate sobre o desenvolvimento sustentável (IBGE, 2013, p.17).

Desta forma, faz necessário de um recorte sobre o uso da terra para avaliar as questões ambientais, assim emerge a bacia hidrográfica como sendo a unidade territorial geográfica em estudo das ações desta pesquisa. As potencialidades, os problemas e necessidades verificadas ao longo deste recorte requerem ações imediatas e mitigadoras que se traduzam em planejamento e ações voltadas à recuperação, conservação ou preservação, na termologia de SANTOS (2013).

A ocupação desordenada do solo em bacias hidrográficas, com rápidas mudanças decorrentes das políticas e dos incentivos governamentais, agrava seus desequilíbrios. Dentre as atividades que causam degradação podem ser citadas as práticas agrícolas, desmatamento, mineração, super-pastoreio e urbanização. O mau uso da terra, desmatamento, mecanização intensa, monocultura, 
descalçamento e corte das encostas para a construção de casas, prédios e ruas são exemplos de atividades humanas que desestabilizam as encostas e promovem ravinas, voçorocas e movimentos de massa (GUERRA e CUNHA, p.360, 2000).

No Brasil, a bacia hidrográfica é unidade territorial para implementação de diversas políticas atuais sob o que decorre da proteção e conservação dos recursos hídricos, no que tange a Política Nacional de Recursos Hídricos e a atuação do Sistema Nacional de Recursos Hídricos. De acordo com a Lei nº 9.433 de 1997 (BRASIL, 1997), a unidade básica para gestão dos recursos hídricos.

Desta forma, PIROLI (2013) considera-se que:

A mesma deve ser adotada como sendo o espaço adequado para o gerenciamento dos demais recursos naturais, uma vez que pode ser definida como uma área com características físicas e biológicas delimitadas pelos seus divisores de água, onde vive e interage o ser humano, e onde as águas superficiais e subterrâneas, são deslocadas, normalmente pela força da gravidade, até um córrego, rio ou reservatório (superficial ou subterrâneo), por canais, que confluem a um curso d'água maior que pode desembocar em um rio principal, em um depósito natural ou artificial de água, em um pântano ou diretamente em um oceano (PIROLI, 2013, p.35).

No Estado de São Paulo, a Política Estadual dos Recursos Hídricos foi instituída pela Lei Estadual Paulista $n^{\circ}$ 7.663/91. No que tange as estruturas de gestão dos recursos hídricos para a legislação do Estado de São Paulo, cabe destacar, também, a existência da Lei $n^{\circ}$ 9.866/97 que consiste em normas e diretrizes para a proteção e recuperação da qualidade ambiental das bacias hidrográficas dos mananciais de interesse regional, para abastecimento da população do próprio Estado de São Paulo. Tem como objetivos principais:

I. Preservar e recuperar os mananciais de interesse regional no Estado de São Paulo;

II. Compatibilizar as ações de preservação dos mananciais de abastecimento e as de proteção ao meio ambiente com o uso e ocupação do solo e o desenvolvimento socioeconômico;

III. Promover uma gestão participativa, integrando setores e instâncias governamentais, bem como a sociedade civil; 
IV. Descentralizar o planejamento e a gestão das bacias hidrográficas desses mananciais, com vistas à sua proteção e à sua recuperação; V. Integrar os programas e políticas habitacionais à preservação do meio ambiente (SÃO PAULO, 1997).

A gestão local da bacia hidrográfica demanda a observação de certas características ambientais, sociais e econômicas e deve-se adorar a esse sistema, pois, compreende a sua área geográfica formada por cursos d'água e seus afluentes, direciona a ocupação humana que se abastece de suas águas, mas para monitorar "a qualidade da água de um manancial depende, portanto, dos usos e atividades desenvolvidas em toda a bacia hidrográfica" (MOTTA, 1995, p. 107).

Diante disso, o geoprocessamento apresenta grande potencialidade de avaliação no que se refere ao monitoramento dos problemas ambientais conforme Piroli (2010) que decorre também em "permitindo a manipulação de diversos dados e informações e também a representação cartográfica destes".

Assim, para auxiliar no levantamento de dados básicos sobre os recursos naturais, o uso do geoprocessamento torna-se mecanismo viável para as análises ambientais e base para futuras tomadas de decisões. Diversos trabalhos utilizando as geotecnologias (que dão suporte ao geoprocessamento) têm sido desenvolvidos para analisar o uso e ocupação das APP e avaliar seus impactos sobre os recursos naturais (PIROLI, 2013, p.28).

Neste contexto, salienta Guerra e Cunha (2000, p.88) que "como agente deteriorador do ambiente, o homem causa vários danos ao solo e a cobertura vegetal natural e, como consequência, tem acelerado a degradação dos recursos naturais e da qualidade de vida"

Com isso, para a presente pesquisa na bacia hidrográfica do ribeirão São Pedro utilizou-se o SIG IDRISI que integra funcionalidades direcionadas às aplicações em SIG e também ao processamento de imagens. Permite analisar, processar e visualizar os mais variados tipos de dados. Além disso, possui um conjunto completo de ferramentas de planejamento territorial, suporte a tomada de decisão e análise de áreas de risco associadas com ferramentas de estatística espacial, análise de superfície e modelagem espacial. 
Com o uso do SIG IDRISI foi possível avaliar, mapear e quantificar o uso da terra da bacia hidrográfica em estudo de forma a obter informações relevantes sobre a conjuntura da área sob seu uso e ocupação. Em se tratando da expressão uso da terra ou uso do solo, (ROSA, 2007), menciona que de forma sintética esta "pode ser entendida como sendo a forma pela qual o espaço está sendo ocupado pelo homem".

A bacia hidrográfica do Ribeirão São Pedro, situada no município de Botucatu, possui uma área de 1393,84 ha. Sua situação geográfica é definida pelas coordenadas: Latitude $22^{\circ} 52^{\prime} 31^{\prime \prime}$ a $22^{\circ} 56^{\prime} 17^{\prime \prime}$ S e Longitudes $48^{\circ} 21^{\prime} 02^{\prime \prime}$ a $48^{\circ} 23^{\prime}$ 28" WGr (Figura 1).

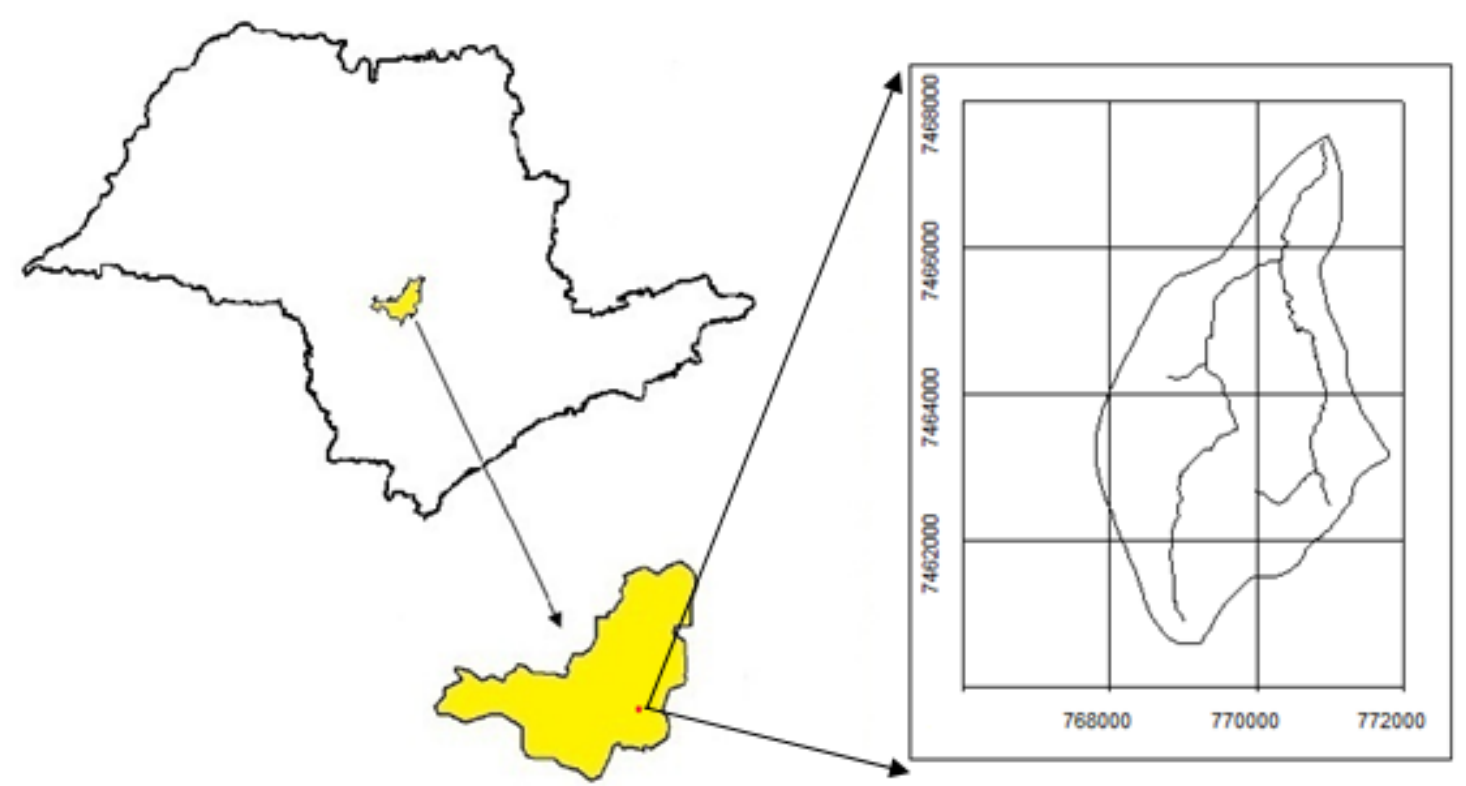

Figura 1 - Localização da microbacia do Ribeirão São Pedro no estado de São Paulo

O clima predominante do município, classificado segundo o sistema Köppen é do tipo Cwa - Clima Mesotérmico de Inverno Seco - em que temperatura do mês mais frio é inferior a $18^{\circ} \mathrm{C}$ e do mês mais quente ultrapassa os $22^{\circ} \mathrm{C}$.

Segundo Piroli (2002), os solos ocorrentes na área foram classificados como: Latossolos Vermelho-Amarelos Distróficos (LVAd1), Neossolos Litólicos Eutróficos 
(RLe), Latossolos Vermelhos Distróficos (LVd) e Neossolos Litólicos Eutróficos (RQotípico).

Os pontos de controle (coordenadas) para o georreferenciamento e os pontos de máxima altitude para digitalização do limite da microbacia tiveram como base a Carta Planialtimétrica em formato digital, editada pelo Instituto Brasileiro de Geografia e Estatística - IBGE (1973), folha de Botucatu (SF-22-R-IV-3), em escala 1:50000.

Utilizou-se a imagem de satélite digital, bandas 3, 4 e 5 do sensor "Thematic Mapper" do LANDSAT - 5, da órbita 220, ponto 76, quadrante A, passagem de 2011 , escala 1:50000.

O mapeamento do uso e ocupação do solo na bacia hidrográfica do ribeirão São Pedro, em 2011, possibilitou identificar cinco (5) classes de usos divididas em mata ciliar, pastagem, reflorestamento, solo exposto e cultura, Figura 2.

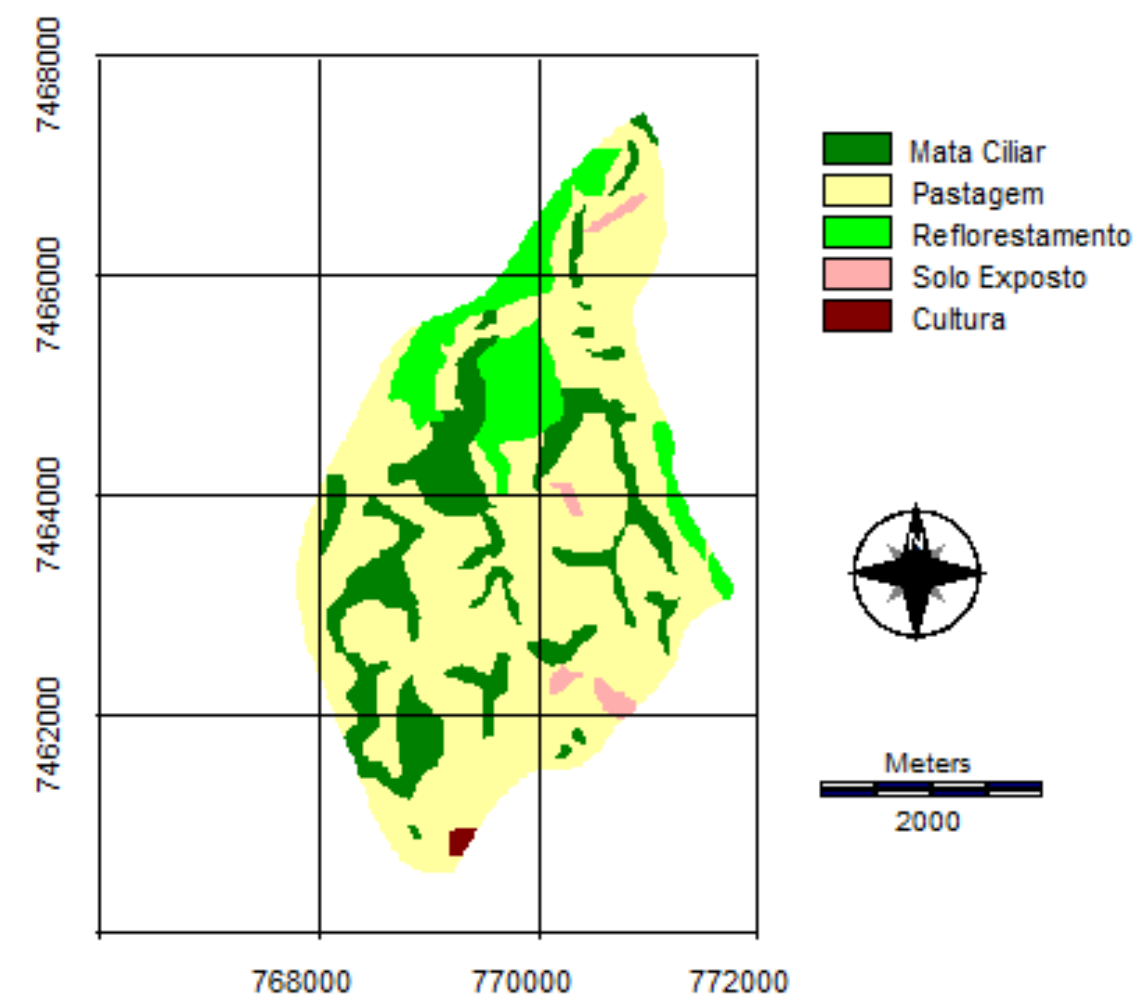

Figura 2 - Mapa de uso e ocupação do solo obtido por imagens de satélite de 2011.

Os resultados do uso da terra na bacia hidrográfica do Ribeirão São Pedro Botucatu (SP) mostraram que a pastagem ocupou a maior parte da área com 
1008,37ha (72,34\%), evidenciando assim o domínio da pecuária regional, revelando solos com baixa fertilidade.

A área reflorestada contribuiu para a paisagem com a adoção de 141,50ha, e a mata ciliar teve aumento em $4 \%$ (de 155,23ha para 218,16ha).

A seguir, na Tabela 1, são apresentados os resultados de uso e ocupação do solo encontrado nas análises de uso e ocupação do solo por meio de imagem de satélite.

Tabela 1 - Distribuição das áreas e porcentagens de uso e ocupação do solo 2011.

\begin{tabular}{ccc}
\hline \multicolumn{3}{c}{ Classes de Uso do solo } \\
\hline Classes & ha & $\%$ \\
Mata Ciliar & 218,16 & 15,65 \\
Pastagem & 1008,37 & 72,34 \\
Reflorestamento & 141,50 & 10,15 \\
Solo Exposto & 21,03 & 1,51 \\
Culturas & 4,78 & 0,35 \\
\hline Total & 1393,84 & 100 \\
\hline
\end{tabular}

Segundo Nardini (2009), o levantamento do uso do solo, em uma determinada região, torna-se um aspecto de interesse fundamental para a compreensão dos padrões de organização do espaço já que o conhecimento das alterações ambientais, provocadas pela ação antrópica, possibilita uma visão dos problemas existentes e produz subsídios para gestão dos recursos naturais. É condição primordial para se programar uma política de uso racional do solo e de respeito à suscetibilidade e capacidade de suporte do meio ambiente aos impactos antrópicos, possibilitando o desenvolvimento sócio-econômico sustentável.

Bucene (2002) destaca a importância do geoprocessamento que se coloca como um importante conjunto de tecnologias de apoio ao desenvolvimento da agricultura, porque permite analisar grandes quantidades de dados georreferenciados, independentemente de serem estatísticos, dinâmicos, atuando de maneira isolada ou em conjunto. Mais do que isto, o geoprocessamento permite o tratamento desses 
dados, gerando informações e possibilitando soluções através de modelagem e simulações de cenários.

\section{CONCLUSÃO}

O presente trabalho procurou contribuir para enfatizar a importância do estudo da unidade territorial que é a bacia hidrográfica por meio de técnicas e ferramentas de sensoriamento remoto e de SIG foram fundamentais para análise do uso e o ocupação da bacia hidrográfica do Ribeirão São Pedro, porém o uso dessa técnica pode ser aplicado a diversos fins, através da utilização de dados ou delimitando áreas para fins de contribuição para o estudo dos usos, legislação, geomorfologia, pedologia entre outros. Desta forma, para concluir, quanto à situação da bacia hidrográfica do Ribeirão São Pedro apresenta maior uso e ocupação da terra para a prática da pastagem o que consequentemente, os solos da área são mais suscetíveis à erosão e enfatiza-se a necessidade de estudos para que as situações apresentada seja alterada por meio por meio de práticas de conservação do meio ambiente.

\section{REFERÊNCIAS}

BERTONI, J.;LOMBRARDI,N.F.Conservação do solo. 4.ed.São Paulo: Ícone,1999.

BOTELHO, R. G. M. Planejamento Ambiental em Microbacia Hidrográfica. In: GUERRA, A. J. T.; SILVA, A. S.; BOTELHO, R. G. M. (Orgs). Erosão e conservação dos solos - conceitos, temas e aplicações. Rio de Janeiro: Bertrand Brasil, 1999. 344p.

GUERRA, A.J.T.;CUNHA, S.B.da (Orgs). Geomorfologia e meio ambiente. Rio de Janeiro: Bertrand Brasil, 2000.

INPE. Instituto Nacional de Pesquisas Espaciais-Divisão de Geração de Imagens (DGI-INPE). Catálogo de Imagens. Disponível em:<http://www.dgi.inpe.br/>. Acesso em: 15 mar. 2013.

INSTITUTO BRASILEIRO DE GEOGRAFIA E ESTATÍSTICA. Carta topográfica. Serviço gráfico do IBGE, 1973. Escala 1:50.000

LEPSCH, I.F. Formação e conservação dos solos.2.ed.São Paulo: Oficina de texto, 2010.

MOTTA, S. Preservação e conservação de recursos hídricos. 2.ed. Rio de Janeiro: ABES, 1995.

NARDINI, R. C. Determinação do conflito de uso e ocupação do solo em Áreas de Preservação Permanente da microbacia do Ribeirão Água -Fria, Bofete (SP) visando a conservação dos 
recursos hídricos. Dissertação (Mestrado em Agronomia) - Faculdade de Ciências Agronômicas, Universidade Estadual Paulista, Botucatu, 2009.

PIROLI, E. L. Geoprocessamento na determinação da capacidade e avaliação do uso da terra do município de Botucatu - SP. Botucatu, 2002, 108 p. Tese (Doutorado em Agronomia/Energia naAgricultura), Faculdade de Ciências Agronômicas, Universidade Estadual Paulista.

PIROLI, E.L. Geoprocessamento aplicado ao estudo do uso da terra das áreas de preservação permanente dos corpos d'água da bacia hidrográfica do rio pardo.Ourinhos, 2013, 150p. Tese apresentada à Universidade Estadual Paulista "Júlio de Mesquita Filho" como parte dos requisitos para obtenção do título de Livre Docente no conjunto de disciplinas Sensoriamento Remoto e Geoprocessamento.

ROSA, R. Introdução ao Sensoriamento Remoto. Uberlândia: Editora da Universidade Federal de Uberlândia, 2003, 228p.

SANTOS, E. P.dos. Mudanças no uso e cobertura da terra na bacia hidrográfica do ribeirão do rebojo entre 1971/1972 e 2007/2008 UGRHI Pontal do Paranapanema- SP. Presidente

Prudente:[s,n],2013.396f.Dissertação apresentada ao Programa de Pós- graduação em Geografia da FCT/UNESP campus de Presidente Prudente como requisito para a obtenção do título de Mestre em Geografia.

SANTOS, E.P.;PIROLI, E.L. Análise do uso e cobertura da terra da bacia hidrográfica do ribeirão do rebojo usando geoprocessamento:uma contribuição ao planejamento ambiental- UGHRI pontal do Paranapanema (SP)- Brasil. Disponível em:<

http://www.revistageonorte.ufam.edu.br/attachments/009_(AN\%C3\%81LISE\%20DO\%20USO\%20E\%2 OCOBERTURA\%20DA\%20TERRA\%20DA\%20BACIA\%20HIDROGR\%C3\%81FICA\%20DO\%20RIBEIR \%C3\%83O\%20DO\%20REBOJO\%20USANDO\%20GEOPROCESSAMENTO\%20UMA\%20CO).pdf>. Acesso em: 20 de agosto de 2014.

SÃO PAULO.LEI no 9.866, DE 28 DE NOVEMBRO DE 1997. Dispõe sobre diretrizes e normas para a proteção e recuperação das bacias hidrográficas dos mananciais de interesse regional do Estado de São Paulo e dá outras providências. 